\title{
Thin Solid Films and Nanomaterials for Solar Energy Conversion and Energy Saving Applications
}

\author{
P. Yianoulis ${ }^{1, a}$ and M. Giannouli, ${ }^{1, b}$ \\ ${ }^{1}$ Solar Energy Laboratory, Physics Department, University of Patras, Patras 26500, Greece \\ Tel: +30 2610997 449, Fax: +30 2610996063 \\ ayianpan@physics.upatras.gr, bmyrtwg@gmail.com
}

received paper 4.10.2007, received revised paper 15.11.2007, accepted date, 22.12.2007

Keywords: Vacuum technology, low-e coatings, solar thermal systems, electrochromic materials, photovoltaics.

\begin{abstract}
Important new applications are possible today in the fields of energy conversion and storage by the application of thin and nanostructured solid films on surfaces. These special films, or multiple films, will be integral parts of the energy systems in the near future for the production of useful thermal and electrical energy and for energy saving applications, especially in buildings. We review the research in this direction. As we are facing the threats of insufficient energy supply and the greenhouse gas emissions from the intense use of fossil sources, we realize that the impacts as well as the future of the solar energy systems have been greatly underestimated. We review the work on solar thermal systems and energy saving applications. The efficient use of solar thermal technologies is very important for the introduction of a sizeable share of environmentally friendly renewable energy sources. New and nano structured materials along with the design and the geometry of advanced systems, capable of achieving high temperatures, as well as on integrated collection and storage systems have been proposed. Recent progress in high-vacuum technology and new materials had a remarkable effect in thin-film quality and cost. As a result new thermal absorbers have appeared along with new evaluation methods. We also present work on low-e coatings and electrochromic thin films that are very important for thermal energy savings in buildings and increase the efficiency of devices. For the photovoltaic solar energy conversion we present results on thin film solar cells and the efforts on dye sensitized nanostructured and organic solar cells.
\end{abstract}

\section{Introduction}

In the near future nanotechnology may contribute to efficient and low-cost systems for generating, storing, and transporting energy. Materials and structures that are designed and fabricated at the nanoscale level and thin films can offer the potential to produce new devices and processes that may enhance efficiencies and reduce costs in many areas, as solar photovoltaic systems, hydrogen production, fuel cells, solar thermal systems and energy saving technologies as low e-coatings and electrochromic devices for smart windows. It is often overlooked that the portion of contribution of renewable energy sources to the total energy budget will come from all possible forms of applications and sources and to be effective it must be combined with energy saving technological breakthroughs.

It is essential to evaluate the energy sources and technologies of conversion, realizing that we may underestimate the contribution and the potential for some of them. For example, wind power is commonly considered more important than solar thermal. However, in terms of worldwide installed capacities and overall energy produced, solar thermal surpasses both wind power and photovoltaic. It is usually less expensive and more energy efficient to exploit the thermal uses of solar energy, 
both direct and indirect as an intermediate step for further transformations.

ESTIF, the European Solar Thermal Industry Federation has published detailed statistics $[1],\left(2^{\text {nd }}\right.$ European Solar Thermal Energy Conference Freiburg, Germany, 21-22 June 2005). The ESTIF statistics cover all EU-25 countries, and present data both in terms of capacity (kilowatt-thermal, $\left.\mathrm{kW}_{\mathrm{th}}\right)$ and in the traditional unit $\left(\mathrm{m}^{2}\right.$ of collector area). We note that the European (EU-25 plus Switzerland) market grew by about $12 \%$ in 2004 and 2005 . For example, $1.110 \mathrm{MW}_{\text {th }}(1.586 .000$ $\mathrm{m}^{2}$ ) of new capacity was installed in Europe in 2004, compared with $991 \mathrm{MW}_{\text {th }}\left(1.415 .598 \mathrm{~m}^{2}\right)$ in 2003. It is obvious that this trend will be amplified more in the future if oil prices continue to rise.

Germany is currently the leader in terms of market volume, (47\% of the European market). It is followed by Greece (14\%), Austria (12\%) and Spain (6\%). In terms of capacity in operation per capita, the European leader is Cyprus, with $430 \mathrm{~kW}_{\mathrm{th}} / 1.000$ inhabitants, followed by Austria and Greece, both at $180 \mathrm{~kW}_{\text {th }} / 1.000$ inhabitants. The EU average is only $21 \mathrm{~kW}_{\text {th }} / 1000$ inhabitants, as the solar thermal market has just started to develop in some countries. Europe is well established in the solar thermal technology, but represents only $9 \%$ of the global market. China alone holds about $80 \%$ of the world market.

Mechanical and electrical power can also be derived from thermal systems. However, large volume exploitation of these systems is still lacking today. Heat storage is another area that may have a tremendous impact in the future. In this article we intend to point out few ideas that have been considered and have made impact already, as well as future trends.

We present in this short paper our work on solar thermal and solar energy materials during the past years. This includes, among other topics, work in the fields of electrochromic (EC) and low emittance coatings, development of materials suitable for energy saving applications in buildings and advanced-glazing. Our experimental facilities include electron beam gun deposition systems, and many other vacuum chambers for thermal deposition and supporting activities.

\section{Thin films and nanotechnology for solar thermal systems}

There are many areas of thin films and nanotechnology that can affect the development of solar thermal conversion as well as of other systems. Today there are many research efforts and ideas that are at the stage of development. Research in nanoscience, nanotechnology and thin films will contribute to the achievement of fundamental breakthroughs in energy systems. Our aim should be to achieve a combination of high efficiency with moderate cost.

Optical systems will play an important role to the design of advanced concentrating systems for high temperature applications and for the indirect conversion to electrical energy. Mirrors and heat mirrors can be created by vacuum deposition of multiple thin films. They can also be used for solar energy collection and energy saving applications. We employ metal $(\mathrm{M})$ thin films $\sim 150 \AA$ Á thick that are partially transparent to solar (visible and near infrared) range of wavelengths. They can be combined with two dielectric layers (D) as a multilayer combination of the form $\mathrm{D} / \mathrm{M} / \mathrm{D}$. The dielectric layers are chosen so that they antireflect partly the metal film in the visible spectral range and increase transmission. At the same time, one of the dielectric layers also protects the metal film. A physical condition imposed on the materials of the dielectric layers is to have high transmittance in the infrared so that it preserves the high reflectance of the metal in the infrared region. We have developed theoretical tools and computer code to calculate the optical properties and to design suitable multilayers. By applying these tools, the multilayer films can be optimized in such a way that the transmitted spectral region is varied for special optical effects. The deposition and optical properties of optimized thin films for energy saving applications have been studied extensively as for example the system $\mathrm{ZnS} / \mathrm{Ag} / \mathrm{ZnS}$ [2]. In general, we obtain results on systems of the type: $\mathrm{ZnS} / \mathrm{M} / \mathrm{ZnS}$ with $\mathrm{M}=\mathrm{Ag}, \mathrm{Al}, \mathrm{Cu}$, and $\mathrm{Au}$. Some results are shown in Figure 1. Other dielectrics that are reported in literature are: $\mathrm{ZnO}, \mathrm{TiO}_{2}, \mathrm{Al}_{2} \mathrm{O}_{3}, \mathrm{Bi}_{2} \mathrm{O}_{3}$ and $\mathrm{SiO}_{2}$. 


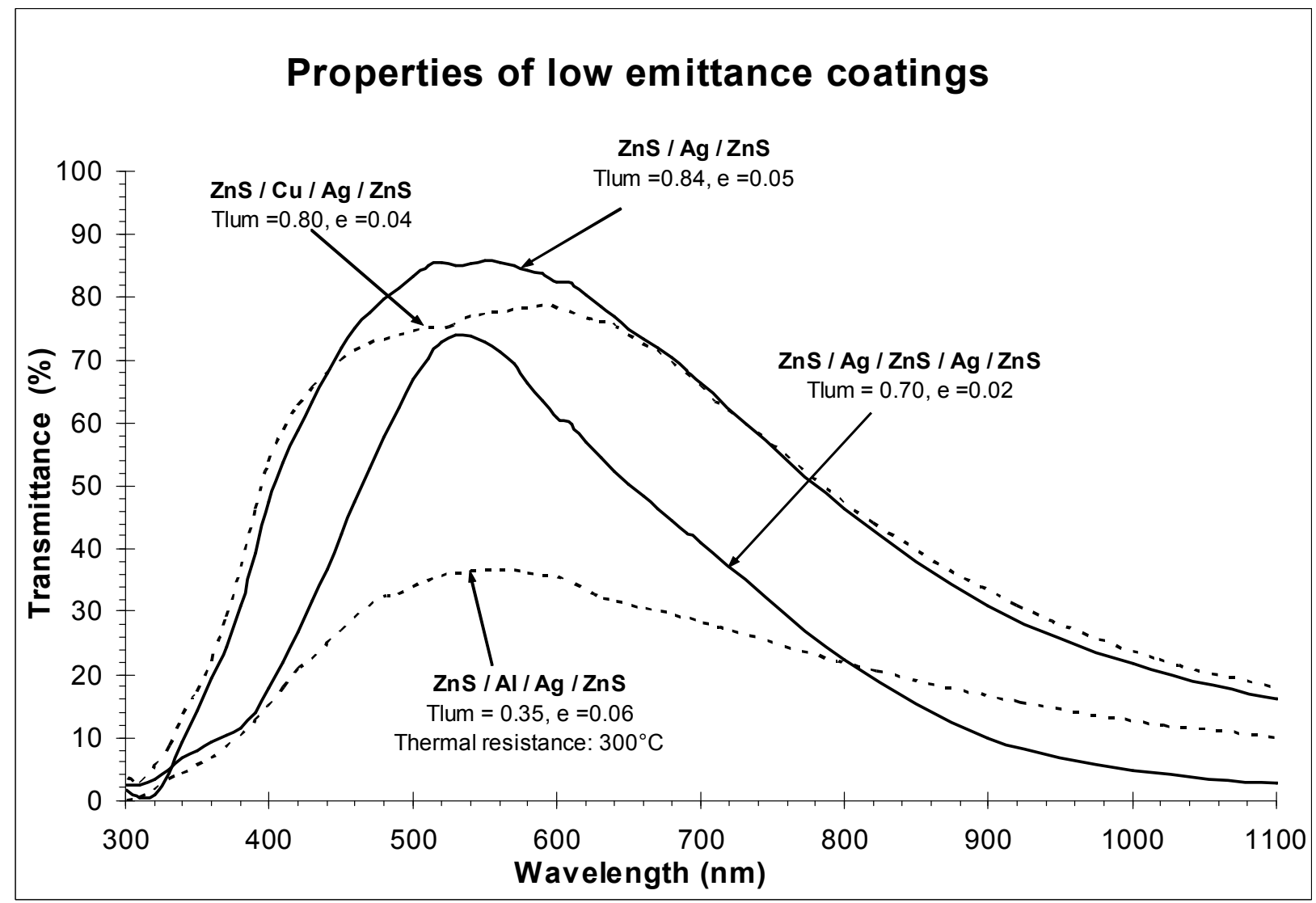

Figure 1 Some results on the transparency as a function of wavelength, for systems of the type: $\mathrm{ZnS} / \mathrm{M} / \mathrm{ZnS}$ and $\mathrm{ZnS} / \mathrm{M}_{1} / \mathrm{ZnS} / \mathrm{M}_{2} / \mathrm{ZnS}$ with $\mathrm{M}, \mathrm{M}_{1}, \mathrm{M}_{2}=\mathrm{Ag}, \mathrm{Al}, \mathrm{Cu}$, and $\mathrm{Au}$.

Polymers like polyvinyl fluoride and chloride, polypropylene and polyethylene, which can be used as an alternative, according to the desired properties of the final products are also used. Today there is an on going search for improved polymers as substrates on which to deposit the films for heat mirrors, reflectors and for other important energy applications as electrochromics, flexible photovoltaics and other devices. The characterization and stability of low-emittance multiple coatings for glazing applications is already in an advanced state [3, 4], as is the integration of lowemittance films in electrochromic devices, as for example the $\mathrm{ZnS} / \mathrm{Ag} / \mathrm{ZnS}$ transparent conductor coatings [5].

A special need arises for transparent electrodes in many applications, including photovoltaics. The multilayer type of the form D/M/D can be used for this purpose, instead of the more traditional doped semiconductor films. Development of multilayer transparent conductive coatings has been described in detail previously [6]. Doped semiconductor films are used: $\operatorname{In}_{2} \mathrm{O}_{3}: \mathrm{Sn}$ (ITO), $\mathrm{SnO}_{2}: \mathrm{F}$, $\mathrm{SnO}_{2}: \mathrm{Sb}$ and others. For these materials we have high charge carrier concentration and mobility greater than $10 \mathrm{~cm}^{2} / \mathrm{V} \cdot \mathrm{sec}$, as well as high lattice relaxation frequency and effective mass. Other materials that may be used are those known to exhibit electrical conduction of Drude-type (like borides, rare earth oxides, carbides and transition metal nitrides).

Another area of interest concerns the design of new absorber surfaces used for photo thermal energy conversion. In this case, accelerated aging tests for solar absorber surfaces are used to estimate the service lifetime of model solar collectors and an acceptable service minimum lifetime of 25 years is set as a limit for designing new absorbers. This service lifetime of an absorber coating is reached if the annual solar fraction of a domestic hot-water system is decreased by $5 \%$ due to deterioration of its optical properties caused by degradation. The absorber can be used after this maximum service lifetime, but at a lower performance. Tests are conducted under different conditions of temperature, humidity, condensation and air containing $\mathrm{SO}_{2}$. 
The IEA Solar Heating and Cooling Programme (IEA SHC) Working Group "Materials in Solar Thermal Collectors" has proposed a procedure based on these tests as a standard to the ISO TC 180 'Solar Energy'. For estimating the acceptable service life of an absorber coating, the IEA SHC Task $\mathrm{X}$ has proposed the performance criterion function (PC): $\mathrm{PC}=-\Delta \alpha+0.25 \Delta \varepsilon<0.05$, where $\alpha$ is the total hemispherical (at air mass 1.5) solar absorptance, and $\varepsilon$ the total hemispherical thermal emittance (at $100{ }^{\circ} \mathrm{C}$ ) of the absorber samples. When the value of the PC function has been increased to 0.05 , the solar fraction of a domestic hot water system has been reduced by around $5 \%$. The absorber is then considered to have considerable degradation in optical performance.

Absorber surfaces made by sputtering deposition systems on an industrial scale (roll coatings) are currently considered the state of the art. Various materials are used for research purposes and many are already in the market. For example, $\mathrm{C} / \mathrm{Al}_{2} \mathrm{O}_{3} / \mathrm{Al}$ has been used, where $\mathrm{C}$ stands for graphite. Also $\mathrm{TiO}_{\mathrm{x}}$, as well as other oxides that have excellent properties, can be deposited to many substrates. They can be combined with a variety of antireflective coatings. The spectral selectivity can be exploited to obtain absorbers that are very efficient for the conversion of solar energy to thermal. We are now in a position to design such absorbers by our theoretical tools and produce the surface coatings by physical vapor deposition, spray pyrolysis or other processes, as electrochemical or sol gel.

\section{Solar thermal collectors}

The most well known application of a solar thermal conversion system is for domestic hot water. It is of interest that the solar thermal conversion technologies have been greatly underestimated. There are so many forms of solar thermal systems and applications in everyday use that we tend to overlook their contribution and their future potential. A partial list of solar thermal devices and applications includes flat plate solar collectors for water and space heating, industrial as well as agricultural uses and concentrating systems for low, intermediate and high concentration and temperatures. In addition, solar ponds and other solar thermal systems can provide heat at a low temperature for various applications. Solar ponds, cookers and dryers are now used in relatively few cases, as oil prices were relatively low until recently.

The field of solar thermal collectors is very dynamic and of special interest, offering direct saving of electrical energy that is used in many circumstances to heat water at relatively low temperatures. Even now, after more than three decades of installation at accelerating rates and the introduction of special tax measures by few countries, some of which were subsequently withdrawn, a large amount of costly electrical energy is consumed for water heating. It is obviously meaningless to produce electricity using expensive solar cells at an average efficiency of $15 \%$, while we can save it in a simple way.

We have worked in this field for many years with the vision of research and development of new and diverse systems that can help spread the use of solar thermal beyond the flat plate collector and at the same time to widen the possible fields of applications. A non-exhaustive short account is given here.

The integrated collector-storage systems were proposed as more effective and esthetically compatible systems that could be designed to suppress thermal losses [7, 8]. The basic goal was to develop simple, inexpensive and durable systems. We have also attempted to use concentrating systems of low concentration and moderate price, as the CPC solar collectors with various absorbers, including the flat bifacial absorbers [9]. It can be shown that we can have an efficiency improvement using stationary concentrating solar collectors without vacuum protection [10]. By implementing the above concepts, low cost solar collector-storage systems can be developed [11]. Double pass solar concentrating collector designs were also proposed, constructed and tested [12]. Stationary concentrating solar air collectors with a low concentration ratio proved to be a viable alternative to the common flat plate collector [13], as well as solar water heaters with booster mirrors [14]. CPC solar collectors with multi channel absorbers [15, 16] and asymmetric reflector solar collectors were validated by outdoor experiments, compared with detailed model calculations 
[17]. Cost effective asymmetric CPC solar collectors were designed and tested further [18]. The modeling of line-axis solar concentrators in the medium temperature range was also examined in detail and compared with experimental data obtained from constructed prototypes [19].

\section{Electrochromic smart windows and passive solar and energy conscious design}

It has been estimated that more than $50 \%$ of the energy needed to run a building can be saved, with moderate costs, using the passive solar design, including energy saving windows. In addition, these buildings provide comfort and a well being feeling to the occupants and increase productivity. More importantly, the reduced use of fossil fuels affects in a positive way the microclimate of the region. The passive solar design is meaningful mainly for new buildings, but many related concepts could be applied during renovation of old buildings, for example advanced glazing when replacing windows. Advanced new materials and devices can be used for energy conservation in buildings. There are many examples as the high performance angular selective window coatings.

The modern passive solar design of buildings includes careful building orientation, use of thermal mass and appropriate openings, fenestration and if possible smart control of the entrance of sunlight and airflows. Heat is stored, when available, and can be used when required. Cooling airflows are also used. Phase change materials can be used for storage of large quantities of heat. Daylighting is the admittance of solar radiation in the interior of buildings making the work or living more enjoyable without artificial lights. The distribution of light should be such that it provides better quality of illumination. This creates in general healthier and more stimulating environment than the energy intensive traditional way. The modern passive solar design of buildings includes careful building orientation, use of thermal mass and appropriate openings, fenestration and if possible smart control of the entrance of sunlight and airflows. Heat is stored, when available, and can be used when required. Cooling airflows are also used. Phase change materials can be used for storage of large quantities of heat.

We have worked mainly on smart windows and especially on the electrochromic films that can be deposited on glass permitting a dynamic control of the light entering the building. An electrochromic window can out-perform the best currently available window systems (in most applications) and has lower annual energy performance than an opaque insulating wall. The primary energy benefits are: reduced cooling, heating and ventilating loads and the ability to reduce electric lighting use by managing daylight admittance. The architectural, functional and aesthetic appeal of a dynamic coating that the electrochromic technology offers is difficult to quantify but it will be a major factor for many buildings in the future. After all many design decisions are made not on the economic basis of but rather on style and appearance.

Thin films of electrochromic oxides, ion storage layers and transparent conductors are important for smart windows and all can be effectively fabricated by vacuum techniques. Appropriate polymer electrolytes are also needed and can be developed by chemical methods. All the above materials must be characterized by advanced methods to provide information on their surface and interface morphology, their structure, composition and physical properties.

Electrochromic devices were fabricated and characterized by electrochemical techniques that determined the coloration efficiency, cycling reversibility and durability of the materials used, as well as the diffusion and mobility parameters of ions into the electrochromic films. Theoretical investigations were carried out to determine the mechanisms of ion transport and coloration of the materials involved and to predict the heat flow through an electrochromic evacuated glazing. A wealth of information was obtained that allowed us to optimize the window properties and choose the most suitable combination of materials. The technique of vacuum sealing is used to provide a durable contiguously sealed double-glazing. Electrochromic evacuated window prototypes with dimensions ranging from $20 \mathrm{~cm} \times 20 \mathrm{~cm}$ and up to $40 \mathrm{~cm} \times 40 \mathrm{~cm}$ were fabricated using a triple glass arrangement in our laboratory.

We have developed and constructed various EC devices. A typical configuration of an electrochromic prototype includes $\mathrm{K}-\mathrm{Glass}^{\mathrm{TM}} / \mathrm{WO}_{3} /$ electrolyte $\mathrm{MgF}_{2} / \mathrm{K}-\mathrm{Glass}^{\mathrm{TM}}$. The speed of 
coloration and bleaching of an EC device is governed by the mobility of the metal ions intercalated into the electrochromic layer. For some of the devices a liquid or gel (polymer) electrolyte supplies lithium ions $\left(\mathrm{Li}^{+}\right)$that intercalate into $\mathrm{WO}_{3}$ when the appropriate voltage is applied. This diffusion process of $\mathrm{Li}$ ions within the $\mathrm{WO}_{3}$ matrix depends on the oxide structure. High degree of disorder, large pores and other extended defects increase the rate of $\mathrm{Li}^{+}$intercalation. Electron beam evaporated $\mathrm{WO}_{3}$ films deposited on substrates at room temperature are amorphous, with a columnar morphology. These characteristics make them suitable for application in EC devices. The typical thickness of the $\mathrm{WO}_{3}$ and $\mathrm{MgF}_{2}$ thin films that we routinely deposit is $350 \mathrm{~nm}$ and $150 \mathrm{~nm}$ respectively, while the electrolyte layer in most of the prototypes is $0.8 \mathrm{~mm}$ thick. In our earlier work we have used various techniques to prepare EC devices, based on $\mathrm{WO}_{3}$ and $\mathrm{MoO}_{3}$ thin films with satisfactory stability and performance. We have also developed devices with ion storage layers, and Ag based low emittance coatings; the last can be used also as transparent conductor for special applications. We developed laboratory prototypes with dimensions up to $40 \mathrm{~cm} \times 40 \mathrm{~cm}$, exhibiting great uniformity and excellent properties. Details on all this work can be found in the literature [20-28]. The equipment used is shown in Figure 2.

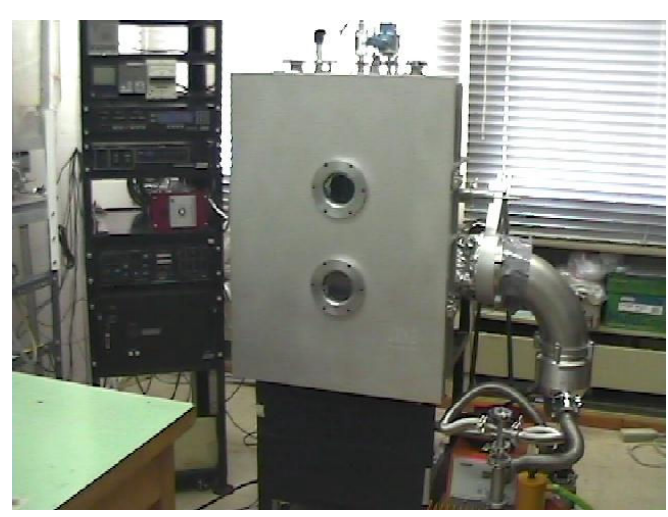

(a)

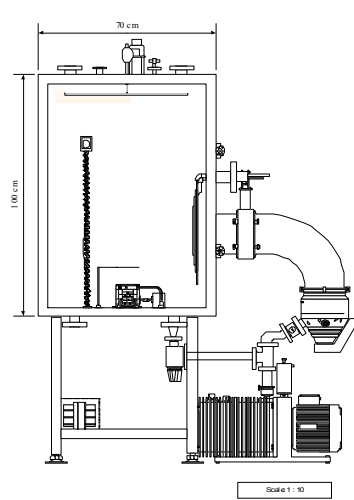

(b)

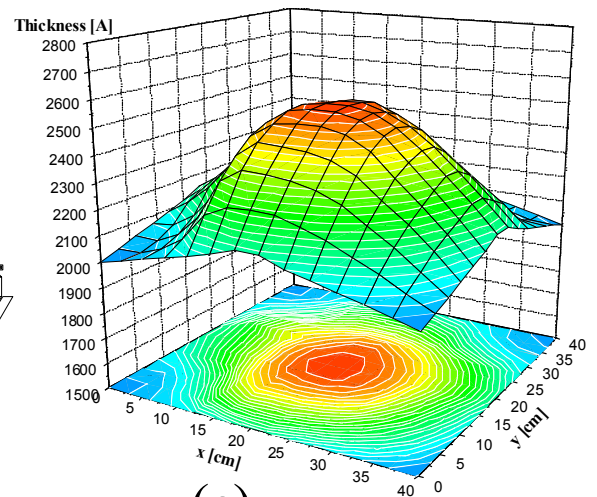

(c)

Figure 2. (a) The vacuum chamber for the fabrication of the $40 \mathrm{~cm} \times 40 \mathrm{~cm}$ electrochromic samples. (b) Schematic representation of the position of the electron beam gun that is used for thin film deposition on glass. (c) Thickness mapping of a sample.

A vacuum glazing using a low emittance film was formed in a special vacuum chamber. One outer glass surface was treated with the active electrochromic material before lamination. Using a polymer electrolyte this was laminated to the third glass sheet with the ion storage layer to produce a combined evacuated electrochromic glazing. The prototypes were tested for durability and performance. A series of experiments were carried out to determine their optical and thermal properties at various coloration stages. The prototypes were tested indoors under a controlled environment and outdoors under real conditions. In both tests, they were subjected to continuous coloration / bleaching cycles to accelerate the aging mechanisms of the active materials. The vacuum integrity after prolonged operation was also assessed. This series of tests provided definitive results for the performance and durability of the devices and was used as feedback for necessary improvements. The study included optimized electrochromic, ion storage and electrode materials and optimized polymer electrolytes. Theoretical models were also developed for the ion transfer from the electrolyte into the electrochromic material. U-values of the window at various coloration stages were found after the fabrication of electrochromic evacuated glazing prototypes, which were assessed for performance and durability. The objective was to develop an electrochromic evacuated glazing that will combine optimum control of the solar radiation penetrating into buildings, with a high degree of thermal insulation. 
Using electrochromic windows as active elements in a building envelope can save up to about half of the energy used for air-conditioning. Better thermal insulation is provided with a reduction of the amount of space heating required during winter. Furthermore, such a glazing will facilitate better daylighting of buildings and offices. A standard electrochromic window will allow a continuous modulation of the luminance between two extreme values during daytime (900 and 300 lux in the bleached and colored state respectively). This can lead to significant improvement of workers productivity and a better feeling for the occupants in general. Improved day lighting can also be achieved by use of larger electrochromic evacuated glazing areas without undesirable increase of solar gain. During early morning and late afternoon hours, the electrochromic glazing can become transparent to improve natural lighting conditions, saving energy that is normally used for artificial lighting. An optimized electrochromic evacuated glazing allows dynamic solar control and can be integrated into the building energy management system, while it is capable to respond to user needs and climatic variations. We have prepared many large $(40 \mathrm{~cm} \times 40 \mathrm{~cm})$ electrochromic samples in our laboratory, such as the one displayed in figure 3 in the coloured and the bleached state.

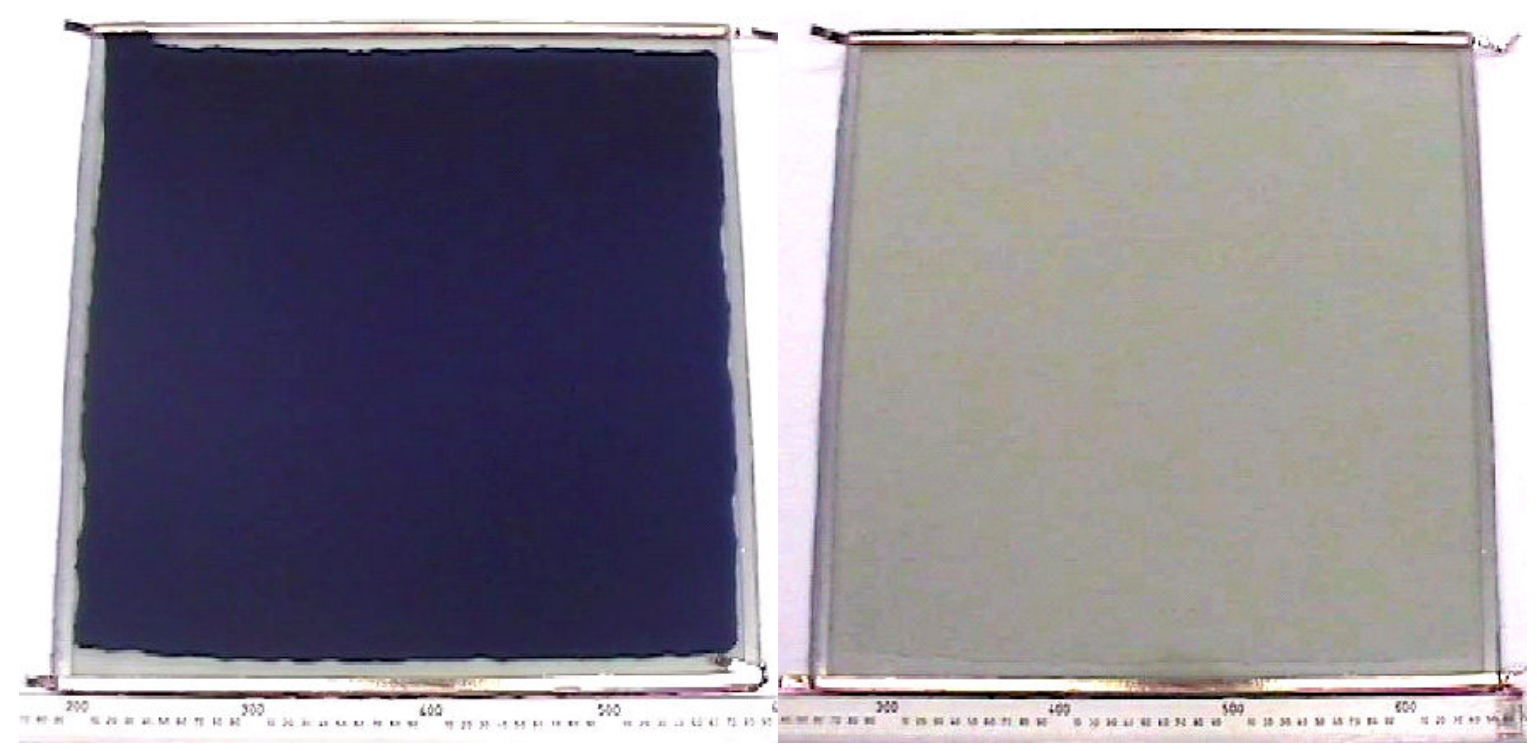

Figure 3. The $40 \mathrm{~cm} \times 40 \mathrm{~cm}$ electrochromic samples in the coloured and the bleached state.

Electrochromic evacuated glazing must be cost competitive, meeting market expectations for solar control window products. Large volume sales in the highly competitive architectural glass market will require pricing to be aggressive. For significant market penetration to occur, electrochromic evacuated glazing prices will need to be reduced by one order of magnitude to around 150 euro $/ \mathrm{m}^{2}$, which is comparable to prices for low-e incorporating mechanical blind systems for light and energy control. Electrochromic windows have several advantages compared to conventional shading and solar control devices. They do not impede visibility, as with blinds and curtains, while it provides glare control and thermal comfort management. It has no moving parts and as a result, they have minimum maintenance costs. It requires low voltage power supply (it can even be powered by photovoltaics) and it can be integrated into the central power management of the building. It has practically infinite coloration stages. It can block both direct and diffuse solar radiation, unlike passive shading devices. It can become transparent during the early morning and afternoon hours, to improve natural lighting conditions, unlike tinted glass. The thermal properties can be evaluated by various methods. We have developed a dynamic simulation method using a suitable test cell that we have constructed and calibrated over the years [29]. In general, the test cell methodology is very important in order to check the results of new technologies and materials [30]. 


\section{High Temperature applications and Solar Furnaces}

There are so many important high temperature applications that we can hardly mention all of them. I shall mention those with a research interest to us. The most common are industrial applications requiring steam under pressure. In order to achieve this, concentrating systems that can follow the sun are designed. Knowledge of the principles of non-imaging optics and ray tracing techniques are routinely used as a design tool. Many shapes and geometries can be used of mainly asymmetric forms and proper reflecting materials must be chosen. Many examples can be found in the literature.

Because of the importance of Hydrogen as a fuel in the future and in relation to our research interest in fuel cells the high-temperature solar thermo chemical water-spitting experiments have been developed. Formation

Solar furnaces are also very important. A solar furnace uses a heliostat that tracks the sun to direct sunlight onto, for example, a mirrored parabolic dish. Because the focal point of the dish can be designed not to move, it is simple to install experiments. The power level of the furnace is adjusted using attenuators that work like a Venetian blind located between the heliostat and the dish other layouts are also used. Applications include investigations of the physical properties of materials in concentrated sunlight, including spectral emissivity and absorptivity, mechanical properties, thermal expansion, conductivity and diffusivity, specific heat and others. Also, the performance and failure thresholds of high-temperature ceramic and special purpose materials, some of which can be nano, can be determined.

The solar thermal power plants are using various concentrating systems. One of the most costeffective is the parabolic trough power plant. A curved trough, which reflects sunlight onto a hollow tube running along above the trough, is used. The trough tilts during the day so that light remains focused on the hollow tube. A working fluid passes through the tube. Heat transfer oil is used. The oil passes through a heat exchanger, creating steam, which runs a steam turbine. Full-scale parabolic trough systems consist of many troughs laid out in parallel. Solar thermal systems using this principle are in operation in many countries. Parabolic trough systems can also create steam directly in the tubes; this concept has been proposed for cheaper overall designs.

Central Tower power plants with Heliostats use an array of flat mirrors to focus the sun's rays upon a collector tower. The concentrated sunlight is absorbed at the top of the tower where a special absorber is placed, heating liquid sodium or other metal of high heat capacity. The energy can be used in steam turbines. This system allows for power generation during the evening. Examples of heliostat power plants are at the 10 to $20 \mathrm{MW}$ in several locations.

Dish systems are also used for the same purpose. A parabolic dish with reflective surface focuses the solar radiation to a point, where an absorber is used to capture the heat. Dish systems can achieve high temperatures due to the higher concentration of light. Typically the dish is coupled with a Stirling engine, but sometimes a steam engine is coupled with the electric generator.

\section{Photovoltaics}

While work is still being done on PV cells based on the classical silicon (Si) technology, which dominates commercially, it appears that this work is reaching its limits. The new ideas about high efficiency cells are now realized in the laboratories.[31] The cost of the commercial production for these devices in the future is expected to be high [32]. However, the market share for highly efficient PV cells is expected to rise in the future. Thin film deposition by modern methods may allow the development of new products for PV solar energy conversion.

The current status of photovoltaics is very interesting for us regarding the field of new and the emerging technologies and materials. In 2006, the worldwide solar photovoltaic industry reached a production $2.1 \mathrm{GW}$ at peak conditions, with an annual growth of about 30 percent for the last ten years. Now, the photovoltaic industry is in the process becoming a mature, mass-producing industry. Currently, the market is dominated by solar cells based on mono and multi-crystalline silicon technologies. The market size and the future growth are of interest to us as well as the 
emerging technologies. It is projected that the demand for non-silicon based solar cells will be strong in the future. Current problems with $\mathrm{Si}$ are centered on the adequate supply of feedstock material. We also look for higher efficiency and cost reduction.

The new emerging solar cell technologies are: Organic and Polymer, Dye-sensitized cells, Nanocrystalline, Thin-film Amorphous, and other Thin-film technologies such as Gallium Arsenide (GaAs), Cadmium Telluride, Copper Indium Gallium Diselenide (CIGS), and Copper Indium Diselenide (CIS).

The prospect of roll-to-roll processing for organic materials is of interest for future photovoltaic devices. However, efficiencies are not yet high enough for organic devices to be commercially viable. One of the possible methods to achieve higher efficiencies could be realized by mixing electron donor type polymers with suitable electron acceptors. Organic solar cells have been developed based on the bulk heterojunction concept of a conjugated polymer and a soluble derivative of the fullerene (C60 or $\mathrm{C} 70$ ) with power conversion efficiencies of about 3\%. Improvement of the energy conversion efficiency of these devices relies on optimizing: the charge carrier generation, the selective transport and collection of charges at the electrodes; and the absorption of light. The generation of electron and hole pairs and their subsequent collection at the opposite electrodes affects the efficiency. Morphology and ordering in the active layer is of interest. One of the factors that play an important role is the entropy of mixing between two polymers. When a polymer blend is spin coated from a well-mixed solution, the faster the solvent evaporates, the less time the polymer has to rearrange itself into discrete domains. Phase separation is then taking place and domain sizes of a few nanometers to several microns are created. Controlling the morphology of the phase separation to achieve an interpenetrating bi-continuous network of donor and acceptor phases on a nanoscale (of the order of $10 \mathrm{~nm}$ ), one can achieve a high interfacial area within a bulk heterojunction blend. Annealing the film after spin-coating, exposure to solvent vapors or controlling the rate of solvent evaporation could alter the morphology of the blend and a phase separation of $10 \mathrm{~nm}$ can be achieved.

Hole transport (p-type) conjugated polymers that have been used are: the poly(p-phenylenevinylene)s (PPVs), poly(p-phenylene)s, polythiophenes as well as their derivates. Poly(3-hexylthiophene) (P3HT) is one of the best candidates due to low energy band gap suitable for red light absorption, the high charge carrier mobility and the excellent solubility in organic solvents. Electron accepting materials (n-type) with high electron affinity have recently been synthesized and investigated. Main chain polyquinoxalines, [33] are representative class of materials, which combine the high electron affinity with high thermal and oxidative stability, outstanding mechanical properties and good film-forming ability [34]. Many oxadiazole- containing polymers have been employed as electron transporting materials in organic light emitting diodes (OLEDs) [35]. This ability to carry electrons is believed to arise from the high electron affinity of the oxadiazole ring in the molecule. However, they exhibit low solubility and poor solution processability. Efforts have been made to incorporate conjugated oligomers into polymers either as polymer backbones or as side chains in order to improve their solubility [36]. As an example, we refer to the synthesis of four main chain 1,3,4-oxadiazole copolyethers by the nucleophilic poly condensation reaction with optical characterization. Moreover, a fluorene copolymer containing 1,3,4-oxadiazole unit (PFOXD) was also synthesized by Suzuki coupling reaction. In addition, a detailed AFM study of the surface morphology of the blends consisted of the regioregular poly(3-hexyl)thiophene with TSTPOXD and PFOXD as thin films was performed. Finally, the photovoltaic response of the TSTPOXD or PFOXD with the P3HT as bulk heterojunction mixtures and a single layer device of the PAFOXD were investigated [37].

Dye-sensitized solar cells present considerable scientific interest. They are based on dyesensitized mesoporous films of $\mathrm{TiO}_{2}$ and are also possible low cost alternatives to conventional solar cell devices. [38]. The fundamental aspects of these cells are connected with the theory of spectral sensitization. The suitability of dye molecules is examined with respect to their energy levels in relation to the semiconductor on which they are adsorbed. Charge transfer from the dye to the semiconductor upon photo-excitation and related phenomena in the dark are important. The 
efficiency of sensitization depends on many factors, such as the form of aggregation and the presence of charged defects. Spectral sensitization is a photo process requiring times of the order of $10^{-10}$ seconds, for the relevant transitions between energy levels. The understanding of the complex phenomena related to the spectral sensitization process is based on the comparison of the energy levels of adsorbed molecules with the corresponding energy levels of the mesoporous films. Figure 4 shows an I-V and power plot for a dye sensitised nanostructured solar cell produced in our laboratory, sensitised with Rodamine B. The fill factor of this particular cell was calculated to be 0.51 .

A distribution of energy levels of the dye molecules exist, with a range of the order of $1 \mathrm{eV}$, due to the Coulomb interaction of the molecules with the defects of the substrate. This results from Quantum Mechanical calculations, followed by Monte Carlo type simulations for the generation of the distribution. The effect of the distribution of energy levels plays a crucial role in the primary electron transfer from the dye to the semiconductor upon photo-excitation. [39-42]

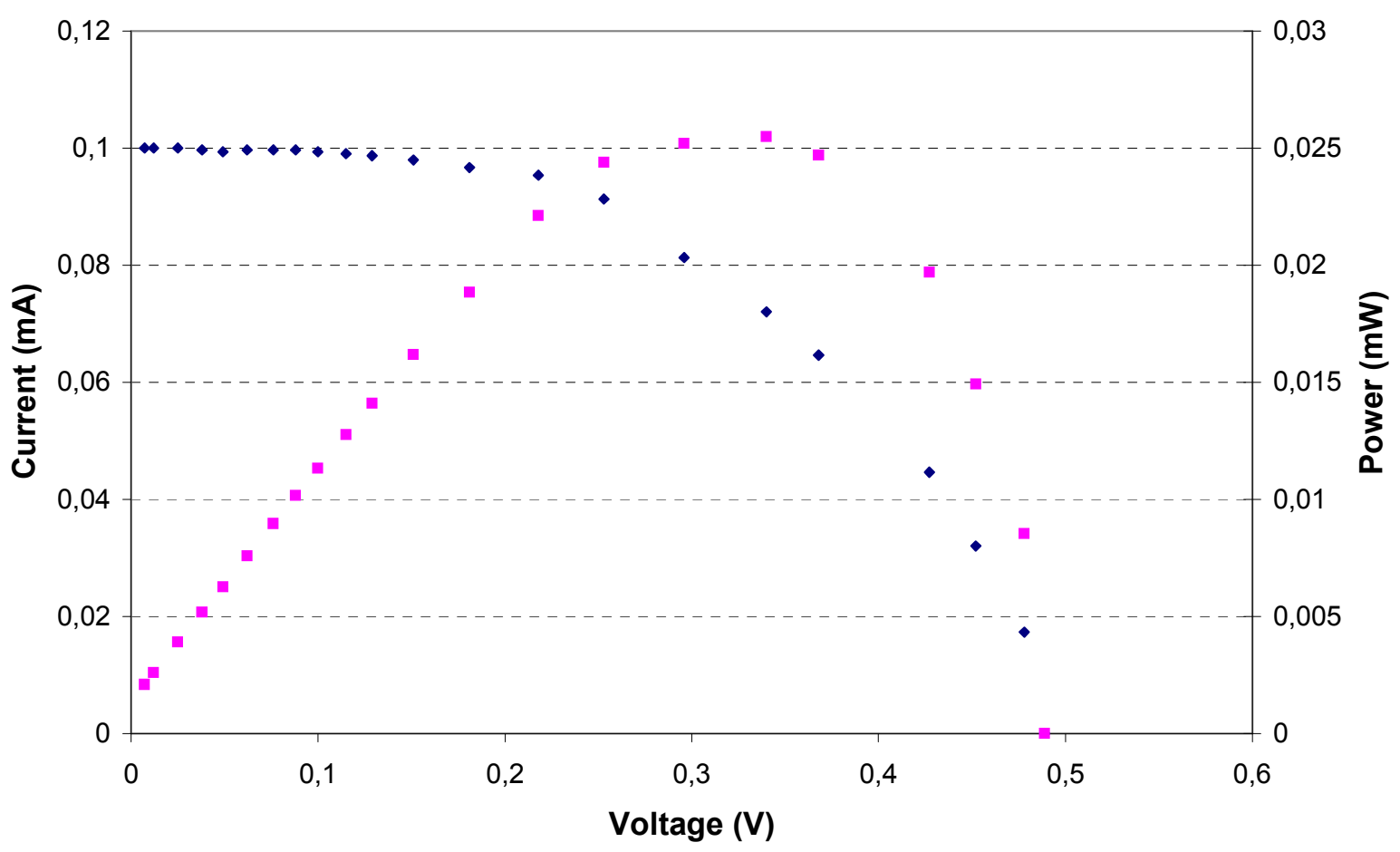

Figure 4. I-V plot for a dye sensitised nanostructured solar cell produced in our laboratory. The power produced by the solar cell is also presented, on the secondary axis

An interesting issue is also the combination of electrical and thermal output. In this category we include the hybrid photovoltaic-thermal collectors (PV-TC) and solar systems [43, 44]. The efficiency of solar cells drops with increasing operating temperatures. Natural circulation of air is the easiest way to remove heat from the PV modules. Hybrid photovoltaic-thermal collector (PVTC) systems are under development in order to achieve high efficiency by simultaneous electricity and heat generation. As the energy efficiency of the systems becomes higher, the cost of production and installation is expected to become more affordable. This is very important for the wider use of solar energy in buildings and for the market penetration of PV. The hybrid systems can give higher efficiencies of photovoltaic conversion to electricity, because they allow the PV panel to work at lower temperatures, while at the same time they can preheat the working fluid, in most cases water or air, for thermal applications. They may be more attractive at places of high ambient temperatures and they can be effective at well-designed installations that consume large quantities of warm 
water, as for example swimming pool heating. Colored solar thermal and hybrid PV-TC systems for aesthetically sensitive applications, as in locations with a special character, for example in the Greek islands, have been also proposed and studied [45]. Diffuse reflectors can also help to increase the radiation per unit PV area, as well as additional transparent covers for increased thermal efficiency [46].

\section{Concluding remarks}

Modern technology in the field of thin film deposition may allow the development of new products for solar energy conversion. The new products are required to have very stringent properties to satisfy users, be cost effective, compete with conventional sources and take into account the environmental concerns. Only in this way the field of solar energy conversion will penetrate the conventional energy system at an expanding rate.

\section{References}

[1] http://www.estec2005.org

[2] G. Leftheriotis, P. Yianoulis, D. Patrikios, Thin Solid Films 306 (1997), p. 92

[3] G. Leftheriotis and P. Yianoulis. Assessment of low-e soft coatings for advanced glazing applications. Proceedings of the 5th World Renewable Energy Congress, Sept. 1998, Florence, Italy, Vol. 3, pp. 1587-1590.

[4] G. Leftheriotis, P. Yianoulis, Solar Energy Materials and Solar Cells 58 (1999), p. 185

[5] G. Leftheriotis, S. Papaefthimiou, P. Yianoulis, Solar Energy Materials and Solar Cells 61 (2000), p. 107

[6] G. Leftheriotis, S. Papaefthimiou, P. Yianoulis, Solid State Ionics 136-137 (2000), p. 655

[7] Y. Tripanagnostopoulos, P. Yianoulis, Solar Energy 48 (1992), p. 31

[8] Y. Tripanagnostopoulos and P. Yianoulis Proc. International Conf.:"Applied Optics in Solar Energy II", Prague, 7-9 July 1987, pp. 297-299.

[9] Y. Tripanagnostopoulos, P. Yianoulis, S. Papaefthimiou, S. Zafeiratos, Solar Energy 69 (2000), p. 191

[10] Y. Tripanagnostopoulos and P. Yianoulis Proc. International Conf.: "Applied Optics in Solar Energy III", Prague, 2-6 October 1989, pp.118-123.

[11] Y. Tripanagnostopoulos and P. Yianoulis. Proceedings of Northsun '90, University of Reading, U.K., 18-21 Sept.1990, Pergamon Press, pp. 346-350.

[12] Y. Tripanagnostopoulos and P. Yianoulis. ISES Solar World Congress, 19-23 August 1991, Denver, Colorado, USA. Vol.2 part II, 2238 (1991).

[13] Y. Tripanagnostopoulos and P. Yianoulis. ISES Int. Conf. Budapest, p.827 (1993)

[14] Y. Tripanagnostopoulos and P. Yianoulis. Int. Conf. WREC III, Reading, UK, Proc. Part III, p.1908 (1994).

[15] Y Tripanagnostopoulos, P. Yianoulis. ISES Solar World Congress, Proc. Abstract p. 159, Harare, Zimbabwe (1995).

[16] Y. Tripanagnostopoulos, P. Yianoulis, Solar Energy 58 (1996), p. 49

[17] P. C. Eames, Y. Tripanagnostopoulos, P. Yianoulis and B. Norton. ISES Solar World Congress, Proc. Abs. 238, Harare Zimbabwe (1995). 
[18] Y. Tripanagnostopoulos, P. Yianoulis, S. Papaefthimiou, M. Souliotis, T. Nousia. Renewable Energy 16 (1999), p. 628

[19] P.C. Eames, B. Norton, Y. Tripagnostopoulos and P. Yianoulis, Renewable Energy 16 (1999), p. 743

[20] A. Siokou, G. Leftheriotis., S. Papaefthimiou, P. Yianoulis, Surface Science 482-485 (2001), p. 294

[21] S. Papaefthimiou, G. Leftheriotis, P. Yianoulis, Electrochimica Acta 46 (2001), p. 2145

[22] S. Papaefthimiou, G. Leftheriotis, P. Yianoulis, Thin Solid Films 343-344 (1999), p. 183

[23] G. Leftheriotis, S. Papaefthimiou, P. Yianoulis, "Advanced electrochromic devices based on $\mathrm{WO}_{3}$ thin films", International Meeting on Electrochromism IME-4, 21-23 August 2000, Uppsala, Sweden.

[24] G. Leftheriotis, S. Papaefthimiou, P. Yianoulis, A. Siokou, Thin Solid Films 384 (2), (2001), p. 298

[25] G. Leftheriotis, S. Papaefthimiou, P. Yianoulis, A. Siokou, D. Kefalas, Applied Surface Science 218 (2003), p. 275

[26] A. Siokou, S. Ntais, S. Papaefthimiou, G. Leftheriotis, P. Yianoulis, Surface Science 566 (2004), p. 1168

[27] E. Syrrakou, S. Papaefthimiou, P. Yianoulis, Solar Energy Materials and Solar Cells 85 (2005), p. 205

[28] S. Papaefthimiou, G. Leftheriotis, P. Yianoulis, Solid State Ionics 139 (1-2), (2001), p. 135

[29] G. Leftheriotis, P. Yianoulis，Solar Energy 69 (2000), p. 295

[30] P.W. Griffiths, M. Di Leo, P. Cartwright, P.C. Eames, P. Yianoulis, G. Leftheriotis, B. Norton, Solar Energy 63 (1998), p. 243

[31] P. Yianoulis and M. Giannouli, World Res. Rev. vol. 15 (2003), p.52

[32] M. A. Green, K. Emery, D. L.King, S. Igari, W. Warta, Prog.Photovolt: Res. Appl. 12 (2004), p. 55.

[33] X .Zhang, AS Shetty, SA Jenekhe. Macromolecules, 32 (1999), p.7422.

[34] W Huang, H Meng, WL Yu, J Pei, ZK Chen, YH Lai, Macromolecules, 32 (1999), p. 118.

[35] Y Hamada, C Adachi, T Tsutsui, S Saito. Jpn J Appl Phys 31 (1992), p.1812.

[36] AP Kulkarni, CJ Tonzola, A Babel, SA Jenekhe. Chem Mater 16 (2004), p. 4556.

[37] C L Chochos, G K Govaris, F Kakali, P Yianoulis, J K Kallitsis, V G Gregoriou Polymer 46 (2005), p. 4654

[38] M. K. Nazeeruddin, A. Kay, R. Rodicio, Humpbry-Baker, E. Miiller, P. Liska, N. Vlachopoulos, and M. Gratzel, J. Am. Chem. Soc. 115, (1993), p.6382

[39] P. Yianoulis and R. C.Nelson, Molec.Phys. 39 (1980), p. 261.

[40] P. Yianoulis and R. C.Nelson, Molec.Phys. 45 (1982), p. 451.

[41] P. Yianoulis, Mol. Cryst. Liq. Cryst. 230 (1993), p. 179.

[42] P.Yianoulis, Mol. Cryst. Liq. Cryst. 218 (1992), p. 73.

[43] Y. Tripanagnostopoulos, P.Yianoulis, and D. Patrikios. Int. Conf. WREC, Proc. Vol. I, 505 508, Denver, USA (1996)

[44] Y. Tripanagnostopoulos, P. Yianoulis, D. Patrikios, Renewable Energy 8 (1996) 505

[45] Y. Tripanagnostopoulos, P. Yianoulis, and D. Patrikios. 4th International Conference on Solar Energy in Architecture and Urban Planning, Proc. 505 - 506, Berlin, 26-29 March, 1996.

[46] Y. Tripanagnostopoulos, Th. Nousia, M. Souliotis, P. Yianoulis, Solar Energy 72 (2002) 217 